\title{
Analisis Tataniaga Tomat Di Kecamatan Sumberejo Kabupaten Tanggamus
}

\section{Analysis of Tomato Trading In Sumberejo District, Tanggamus Regency}

\author{
Anisah Ramadona ${ }^{1}$, Sutarni ${ }^{1}$,dan Muhammad Zaini ${ }^{1}$ \\ ${ }^{1}$ State Polytechnic of Lampung \\ *E-mail : Ramadonaanisah@gmail.com
}

\begin{abstract}
Sumberejo District is one of the highest tomato production centers in Tanggamus Regency. Tomato trading activities are faced with the problem of fluctuating prices and limitations of trading channels at the farmer level, so it is necessary to analyze the tomato trading system if it is seen from the high amount of production in Sumberejo District. The purpose of this research is to identify the trading system activity in the tomato trading system and channel, calculate the margin of the tomato trading system in each trading channel, analyze the efficiency level of the tomato trading channel in each trading channel, analyze the elasticity of price transmission and market structure in the District of Sumberejo. Tanggamus Regency. The research method used is qualitative and quantitative methods. Purposive determination of the location. The sampling method for farmers was simple random (simple random sampling). The data collection method in this research is to collect primary data and secondary data. The trading activities carried out by farmers include selling tomatoes, assuming risks, and financing. Trading activities in a trading system include selling tomatoes, buying tomatoes, transporting, weighing, taking risks, financing, and market information. There are 3 trading channels formed in Sumberejo District. The trading channel I consists of farmer-traders, gatherers-retailers-consumers. Channel II consists of farmer-wholesaler-retailer. Channel III consists of farmer-trader-gatherer-wholesalerconsumer. The margin values for the trading channel I, the trading channel II, and the trading channel III, each obtained a margin of $R p$ 3,000, Rp 3,000 and Rp 4,000. Based on several indicators and the value of marketing efficiency, the trading channel II is an efficient channel compared to channels I and III. The value of price transmission elasticity is 0.785 $(E t<1)$. In general, the structure of the tomato market leads to imperfect competition, namely the oligopsony market)
\end{abstract}

Keywords: market structure, price transmission elasticity, tomatoes, trading system

Disubmit : 8 Maret 2021; Diterima: 26 Maret 2021; Disetujui : 26 April 2021

\section{PENDAHULUAN}

Tomat termasuk salah satu hasil pertanian yang nilainya ekonominya cukup tinggi dan banyak dikonsumsi oleh masyarakat Indonesia sebagai sumber vitamin dan mineral. Komoditas tomat merupakan salah satu komoditas hortikultura yang memiliki produksi yang cukup tinggi yaitu sebesar 962.845 ton di Indonesia (Badan Pusat Statistik dan Direktorat Jenderal Hortikultura, 2018). Produksi tomat terbanyak diserap oleh pasar lokal, salah satu provinsi di Indonesia yang merupakan penghasil tomat dengan jumlah produksi yang cukup melimpah yaitu Provinsi Lampung. Menurut Badan Pusat Statistik dan Direktorat 
Jenderal Hortikultura pada tahun 2017 diketahui bahwa Provinsi Lampung merupakan sentra produksi hortikultura khususnya tomat dengan urutan ke delapan di Indonesia. Jumlah produksi tomat di Provinsi Lampung dalam kurun 5 tahun terakhir ini mengalami peningkatan jumlah produksi yaitu Jumlah produksi tomat tertinggi tercapai pada tahun 2017 yaitu sebesar 25,432 ton/ha. Hal ini menunjukkan bahwa Provinsi Lampung mampu memanfaatkan lahan pertanian serta teknologi yang baik untuk ditanami dengan komoditas tomat. Provinsi Lampung yang merupakan sentra produksi tomat terdapat di Kabupaten Tanggamus dengan urutan produksi tomat terbesar kedua setelah Lampung Barat (BPS Provinsi Lampung, 2016).

Luas panen dan produksi tomat per Kecamatan di Kabupaten Tanggamus tahun 2017 dapat diketahui bahwa jumlah produksi tomat tertinggi berada pada Kecamatan Sumberejo yang merupakan sentra produksi tomat di Kabupaten Tanggamus dengan jumlah produksi sebanyak 7.108 ton dan produktivitas sebesar 236,9 ton/ha (BPS Kabupaten Tanggamus, 2018). Oleh karena itu petani di wilayah kecamatan sumberejo memiliki peluang dan kesempatan yang kuat untuk menanam tomat dibandingkan dengan kecamatan lainnya. Permasalahan yang dihadapi oleh petani sayuran khususnya komoditas tomat menyangkut fluktuasi harga, faktor cuaca dan iklim juga turut mempengaruhi harga tomat dan hal tersebut menjadi kekhawatiran sendiri bagi petani. Harga tomat pada tahun 2018 sampai dengan bulan september tahun 2020 di Kabupaten Tanggamus pada tingkat produsen sebesar Rp 4.153/kg dan harga eceran rata-rata yaitu sebesar Rp7.117/Kg (Dinas Pertanian dan Pangan Kabupaten Tanggamus, 2020). Harga tomat di Kabupaten Tanggamus terus mengalami fluktuasi yang disebabkan oleh berbagai faktor penyebab, diantaranya di dalam sistem pemasaran tomat terdapat banyak lembaga pemasaran yang terlibat, sehingga pembagian margin pemasaran menjadi tidak merata dan berpengaruh pada tingkat fluktuasi harga yang berpengaruh pada penerimaan petani serta mengenai keterbatasan saluran tataniaga dalam memasarkan tomat, sebagian besar petani tidak memiliki alternatif lain selain menjual tomatnya kepada pedagang pengumpul. Perubahan harga pada tingkat konsumen yang terjadi tidak sepenuhnya diteruskan ke produsen atau bisa disebutkan bahwa transmisi harga yang berlangsung tidak sempurna (Rahayu, 2018).

Penelitian terkait diberbagai tempat telah dilakukan mengenai analisis pemasaran tomat, hasil analisis pemasaran tersebut menunjukkan bahwa saluran pemasaran yang efisien merupakan saluran pemasaran yang pendek sehingga dapat memberi peluang peningkatan bagian harga ditingkat petani (Elisa, Hadayani, \& Effendy, 2016). Oleh karena itu perlu dilakukannya penelitian untuk menganalisis apakah sistem tataniaga tomat di daerah penelitian sudah efisien dan mengidentifikasi tingkat harga yang dapat diterima oleh petani dari masing-masing saluran tataniaga yang terlibat. Rumusan masalah dalam penelitian ini yaitu diantaranya, apa saja aktivitas tataniaga yang dilakukan lembaga tataniaga di Kecamatan Sumberejo Kabupaten Tanggamus, bagaimana bentuk saluran tataniaga tomat di Kecamatan Sumberejo Kabupaten Tanggamus, berapa besar margin tataniaga tomat pada masing-masing saluran tataniaga, bagaimana tingkat efisiensi saluran pemasaran tomat, dan bagaimana struktur pasar serta elastisitas transmisi harga yang terjadi pada tataniaga tomat.

Adapun tujuan dari penelitian ini yaitu mengidentifikasi aktivitas tataniaga pada lembaga tataniaga dan saluran tataniaga tomat di Kecamatan Sumberejo Kabupaten Tanggamus, menghitung margin tataniaga tomat pada masing-masing saluran tataniaga, menganalisis tingkat efisiensi saluran tataniaga tomat pada masing- masing saluran tataniaga, dan menganalisis elastisitas transmisi harga dan struktur pasar di Kecamatan Sumberejo Kabupaten Tanggamus.

\section{METODE PENELITIAN}

Penelitian ini dilaksanakan di Desa Simpang Kanan, Kecamatan Sumberejo Kabupaten Tanggamus. Penelitian ini dilaksanakan pada bulan Oktober 2019 sampai dengan Februari 2020. Metode penelitian yang digunakan adalah metode kualitatif dan kuantitatif. Penentuan lokasi secara sengaja (purposive), pemilihan Desa Simpang Kanan berdasarkan pertimbangan informasi dan data dari BP3K bahwa Desa Simpang Kanan 
merupakan salah satu desa penghasil sayuran yang potensial, dan sebagian besar kelompok tani nya memiliki kemampuan bertani dengan kelas lanjut. Metode pengumpulan data pada penelitian ini adalah dengan mengumpulkan data primer dan data sekunder.

Pengambilan sampel responden untuk petani pada penelitian ini menggunakan metode secara acak sederhana (simple random sampling), yang dilakukan dengan cara mengambil sebanyak $10 \%$ dari jumlah populasi petani (populasi=180) yang ada karena jumlahnya besar. Menurut pendapat Arikunto (2008) apabila populasi <100 maka lebih baik diambil semua, dan jika jumlah populasinya besar dapat diambil antara $10-15 \%$ atau $20-55 \%$. Sehingga sampel responden untuk petani yaitu sebanyak 18 petani. Penentuan sampel lembaga tataniaga dilakukan dengan menggunakan metode snowball sampling yaitu cara pengambilan sampel yang pada awalnya menggunakan sejumlah kecil individu atau kelompok orang untuk ditanyakan menyangkut hal-hal tertentu, kemudian individu atau kelompok tersebut diminta untuk menunjukkan individu atau kelompok lain yang mereka kenal dan mengerti tentang seluk-beluk masalah yang ditanyakan. Berdasarkan keadaan di lokasi penelitian informasi mengenai lembaga tataniaga yang terlibat terdapat pedagang pengumpul 5 orang, pedagang besar 5 orang, dan pedagang pengecer 5 orang. Sehingga informan lembaga tataniaga yang ada di lokasi penelitian diambil semua sebagai sampel dalam penelitian ini dengan total sebanyak 15 orang.

Metode pengumpulan data pada penelitian ini adalah dengan mengumpulkan data primer dan data sekunder. Metode analisis data yang digunakan untuk menjawab tujuan pertama yaitu menggunakan metode kualitatif secara deskriptif yang digunakan untuk mengetahui aktivitas tataniaga dan saluran tataniaga tomat di Kecamatan Sumberejo dilakukan dengan cara mengikuti aliran produksi tomat dari petani sampai konsumen akhir. Metode analisis data yang digunakan untuk menjawab tujuan kedua adalah menghitung margin tataniaga tomat dengan menggunakan metode kuantitatif dengan pendekatan rumus sebagai berikut:

\section{Margin Tataniaga}

Margin tataniaga merupakan selisih harga ditingkat konsumen dan harga di tingkat produsen (Fitriani, Ismono, \& Rosanti, 2011). Perhitungan margin dari setiap lembaga pemasaran digunakan rumus pendekatan margin pemasaran sebagai berikut:

$$
\begin{aligned}
& \mathrm{Mj}_{\mathrm{i}}=\mathrm{Ps}_{\mathrm{i}}-\mathrm{Pb}_{\mathrm{i}} \text { atau } \\
& \mathrm{Mji}=\mathrm{bt}_{\mathrm{i}}+\pi_{\mathrm{i}}
\end{aligned}
$$

Keterangan :

$$
\begin{array}{ll}
\mathrm{Mj}_{\mathrm{i}} & =\text { Margin pemasaran pada lembaga pemasaran tingkat ke-i }(\mathrm{Rp} / \mathrm{kg}) \\
\mathrm{PS}_{\mathrm{i}} & =\text { Harga jual pada lemabaga pemasaran tingkat ke-i }(\mathrm{Rp} / \mathrm{kg}) \\
\mathrm{Pb}_{\mathrm{i}} & =\text { Harga beli pada lembaga pemasaran tingkat ke-i }(\mathrm{Rp} / \mathrm{kg}) \\
\mathrm{bt}_{\mathrm{i}} & =\text { Biaya pemasaran pada lembaga pemasaran tingkat ke-i }(\mathrm{Rp} / \mathrm{kg}) \\
\pi_{\mathrm{i}} & =\text { Keuntungan pemasaran pada lembaga pemasaran tingkat ke- }(\mathrm{Rp} / \mathrm{kg})
\end{array}
$$

\section{Farmer share}

Analisis Farmer's Share bermanfaat untuk mengetahui bagian harga yang diterima oleh petani dari harga di tingkat konsumen yang dinyatakan dalam persentase (\%)(Anindita, 2017). Farmer's share diformulasikan sebagai berikut:

$$
\begin{aligned}
& \text { FS } \quad=\frac{\text { Pf }}{\operatorname{Pr}} \times 100 \% \\
& \text { Keterangan : } \\
& \text { Fs } \quad=\text { Bagian harga yang diterima petani } \\
& \text { Pf } \quad=\text { Harga ditingkat petani } \\
& \text { Pr } \quad=\text { Harga konsumen akhir }
\end{aligned}
$$


Metode analisis data yang digunakan untuk menjawab tujuan ketiga adalah menganalisis tingkat efisiensi saluran tataniaga. Efisiensi tataniaga merupakan suatu ukuran keberhasilan yang dinilai dari segi besarnya sumber/biaya untuk mencapai hasil dari kegiatan yang dijalankan(Soekartawi, 2002). Besarnya efisiensi pemasaran dapat dirumuskan sebagai berikut :

$$
\mathrm{Ep}=(\mathrm{Bp} / \mathrm{Np}) \mathrm{X} 100 \%
$$

Keterangan :

Ep $=$ Efisiensi pemasaran

$\mathrm{BP}=$ Biaya Pemasaran

$\mathrm{NP}=$ Nilai Produk yang dipasarkan

Metode analisis data yang digunakan untuk menjawab tujuan keempat adalah menganlisis elastisitas transmisi harga dan struktur pasar dengan menggunakan pendekatan sebagai berikut:

\section{Elastisitas transmisi harga}

Elastisitas transmisi harga merupakan perbandingan perubahan persentase dari harga di tingkat pengecer/pemasar/konsumen dengan perubahan harga di tingkat petani/produsen (Sinaga \& Dewi, 2016). Data harga yang digunakan untuk regresi sederhana yaitu data harga pada bulan Januari tahun 2018 sampai dengan data harga pada bulan September $2020(n=33)$.

Rumus elastisitas transmisi harga sebagai berikut:

$$
\mathrm{Et}=\beta \frac{\mathrm{Pr}}{\mathrm{Pf}}
$$

Keterangan :

$\mathrm{Et}=$ elastisitas transmisi harga

$\mathrm{Pf}=$ harga di tingkat petani

$\operatorname{Pr}=$ harga di tingkat retail/pengecer

b1 = koefisien regresi

\section{Struktur pasar}

Struktur pasar pada tugas akhir ini dianalisis secara deskriptif yaitu dengan dengan melihat beberapa indikator, yaitu jumlah lembaga pemasaran, differensiasi produk, dan kondisi keluar masuk pasar.

\section{HASIL DAN PEMBAHASAN Aktivitas Tataniaga}

Tataniaga tomat di Kecamatan Sumberejo dari petani hingga menyalurkan ke tangan konsumen melibatkan beberapa lembaga tataniaga yaitu diantaranya pedagang pengumpul, pedagang besar, dan pedagang pengecer. Aktivitas tataniaga merupakan kegiatan yang dilakukan oleh lembaga tataniaga selama melakukan proses tataniaga. Secara rinci aktivitas tataniaga pada masing-masing lembaga tataniaga dapat dilihat pada Tabel 1.

Tabel 1. Aktivitas tataniaga pada masing-masing lembaga tataniaga

\begin{tabular}{llllllll}
\hline \multirow{2}{*}{ Lembaga tataniaga } & \multicolumn{7}{c}{ Aktivitas tataniaga } \\
\cline { 2 - 8 } & Jual & Beli & Timbang & Angkut & Risiko & Pembiayaan & Informasi pasar \\
\hline Petani & V & - & - & - & V & V & - \\
Pengumpul & V & V & V & V & V & V & V \\
Pedagang Besar & V & V & V & V & V & v & v \\
Pengecer & V & V & V & V & v & V & v \\
\hline
\end{tabular}

Sumber: Data diolah, 2020

Tabel 1 menjelaskan bahwa aktivitas tataniaga yang dilakukan pada masing-masing lembaga tataniaga di Kecamatan Sumberejo mulai dari petani, pedagang pengumpul, pedagang besar, dan pengecer meliputi aktivitas penjualan, aktivitas pembelian, aktivitas pengangkutan, penanggungan risiko, penyediaan biaya, 
dan informasi pasar. Perbedaan aktivitas tataniaga pada tingkat petani dan tingkat lembaga tataniaga lainnya cenderung sama hanya terdapat perbedaan pada tingkat petani tidak menjalankan aktivitas pengangkutan hasil panen tomat, penimbangan, dan informasi pasar.

\section{Saluran Tataniaga}

Saluran tataniaga tomat dilakukan mulai dari produsen hingga sampai ke tangan konsumen akhir. Produsen dalam tataniaga tomat adalah petani yang menghasilkan produksi tomat untuk didistribusikan dan dipasarkan melalui saluran tataniaga. Saluran tataniaga merupakan suatu rangkaian atau alur dari lembaga tataniaga maupun organisasi yang terlibat pada proses pemasaran produk barang atau jasa hingga sampai ke konsumen akhir. Saluran tataniaga yang terbentuk di Kecamatan Sumberejo, Kabupaten Tanggamus melibatkan beberapa lembaga-lembaga tataniaga yaitu antara lain pedagang pengumpul, pedagang besar, dan pedagang pengecer. Berdasarkan penelitian ini diperoleh tiga saluran tataniaga tomat di Kecamatan Sumberejo, hal ini sesuai dengan penelitian (Sutarni, Saty, \& Unteawati, 2018) bahwa saluran distribusi agribisnis ikan patin di lokasi penelitian juga memiliki beberapa pola atau lebih dari satu pola saluran. Saluran tataniaga tomat yang terbentuk di Kecamatan Sumberejo antara lain sebagai berikut:

1) Saluran tataniaga pola I : petani-pedagang pengumpul - pedagang pengecer-konsumen

2) Saluran tataniaga pola II : petani - pedagang besar - pedagang pengecer- konsumen

3) Saluran tataniaga pola III: petani-pedagang pengumpul - pedagang besar - pedagang pengecerkonsumen

\section{Margin Tataniaga}

Margin tataniaga diperoleh dengan cara melakukan pengurangan antara harga jual pada setiap lembaga tataniaga dengan harga beli yang diperoleh. Margin tataniaga juga merupakan selisih antara harga yang dibayarkan oleh konsumen dengan harga yang diterima oleh produsen/petani. Kegiatan analisis margin tataniaga dilakukan dari tingkat petani, pedagang pengumpul, pedagang besar, dan pedagang pengecer. Hasil analisis margin tataniaga dilakukan dengan tujuan untuk mengetahui tingkat efisiensi tataniaga di Kecamatan Sumberejo.

Tabel 2 menjelaskan bahwa pada saluran tataniaga I, petani yang bertindak sebagai produsen tidak mengeluarkan biaya tataniaga. Biaya tataniaga tersebut ditanggung oleh pedagang pengumpul, lembaga tataniaga pada saluran I yang terlibat dalam memasarkan tomat yaitu antara lain petani, pedagang pengumpul, dan pedagang pengecer. Besarnya biaya tataniaga yang dikeluarkan oleh pedagang pengumpul pada saluran I yaitu Rp 457,24/kg tomat. Biaya-biaya yang dikeluarkan tersebut terdiri dari biaya transportasi, biaya bongkar muat, upah kuli panggul, biaya tenaga kerja biaya peti, biaya penyusutan peralatan, dan biaya retribusi.

Berdasarkan perhitungan margin tataniaga pada masing-masing saluran tataniaga yang telah dilakukan maka dapat disimpulkan bahwa saluran tataniaga yang memiliki nilai margin paling besar yaitu terdapat pada saluran tataniaga pola III dengan jumlah margin tataniaga sebesar Rp 4.000. Pada saluran tataniaga pola I dan pola II diperoleh jumlah margin masing-masing sebesar Rp 3.000. Nilai margin tataniaga yang besar pada saluran pola III disebabkan karena pada saluran tersebut banyak melibatkan lembaga tataniaga dibandingkan dengan saluran pola I dan II. Semakin panjang rantai tataniaga maka margin yang diperoleh akan semakin besar, hal ini sesuai dengan penelitian (Andhika et al, 2014) yang menyebutkan bahwa rantai tataniaga yang panjang akan menghasilkan nilai margin tataniaga yang besar. 
Tabel 2. Margin tataniaga pada masing-masing saluran tataniaga

\begin{tabular}{|c|c|c|c|c|c|c|}
\hline \multirow{2}{*}{ Uraian } & \multicolumn{2}{|c|}{ Saluran pola I } & \multicolumn{2}{|c|}{ Saluran pola II } & \multicolumn{2}{|c|}{ Saluran pola III } \\
\hline & $\mathrm{Rp} / \mathrm{Kg}$ & $\%$ & $\mathrm{Rp} / \mathrm{Kg}$ & $\%$ & $\mathrm{Rp} / \mathrm{Kg}$ & $\%$ \\
\hline \multicolumn{7}{|l|}{ Petani } \\
\hline Harga jual & $6.000,00$ & 66,67 & $6.000,00$ & 66,67 & $5.000,00$ & 55,56 \\
\hline \multicolumn{7}{|l|}{ Pedagang Pengumpul } \\
\hline Harga beli & $6.000,00$ & 66,67 & & & $5.000,00$ & 55,56 \\
\hline Biaya tataniaga & 457,24 & 5,08 & & & 403,37 & 4,48 \\
\hline Keuntungan & $1.042,76$ & 11,59 & & & 596,63 & 6,63 \\
\hline Ratio profit margin & 2,28 & 0,03 & & & 1,48 & 0,02 \\
\hline Margin tataniaga & $1.500,00$ & 16,67 & & & $1.000,00$ & 11,11 \\
\hline Harga jual & $7.500,00$ & 83,33 & & & $6.000,00$ & 66,67 \\
\hline \multicolumn{7}{|l|}{ Pedagang Besar } \\
\hline Harga beli & & & $6.000,00$ & 66,67 & $6.000,00$ & 66,67 \\
\hline Biaya tataniaga & & & 164,04 & 1,82 & 171,89 & 1,91 \\
\hline Ratio profit margin & & & 5,10 & 0,06 & 7,73 & 0,09 \\
\hline Keuntungan & & & 835,96 & 9,29 & $1.328,11$ & 14,76 \\
\hline Margin tataniaga & & & $1.000,00$ & 11,11 & $1.500,00$ & 16,67 \\
\hline Harga jual & & & $7.000,00$ & 77,78 & $7.500,00$ & 83,33 \\
\hline \multicolumn{7}{|l|}{ Pedagang Pengecer } \\
\hline Harga beli & $7.500,00$ & 83,33 & $7.000,00$ & 77,78 & $7.500,00$ & 83,33 \\
\hline Biaya tataniaga & 979,93 & 10,89 & 324,29 & 3,60 & 439,59 & 4,88 \\
\hline Keuntungan & 520,07 & 5,78 & $1.675,71$ & 18,62 & $1.060,41$ & 11,78 \\
\hline Ratio profit margin & 0,53 & 0,01 & 5,17 & 0,06 & 2,41 & 0,03 \\
\hline Margin tataniaga & $1.500,00$ & 16,67 & $2.000,00$ & 22,22 & $1.500,00$ & 16,67 \\
\hline Harga jual & 9.000 & 100,00 & 9.000 & 100,00 & 9.000 & 100,00 \\
\hline Konsumen & 9.000 & & 9.000 & & 9.000 & \\
\hline Total Biaya Tataniaga & $1.437,17$ & & 488,33 & & $1.014,84$ & \\
\hline Total Keuntungan & $1.562,83$ & & $2.511,67$ & & $2.985,16$ & \\
\hline Total Margin & 3.000 & & 3.000 & & 4.000 & \\
\hline Total Ratio Profit Margin & 2,81 & & 10,26 & & 11,62 & \\
\hline
\end{tabular}

Sumber : Data diolah, 2020

\section{Farmer share}

Analisis farmer share digunakan untuk melihat persentase harga yang diterima oleh petani yang bertindak sebagai produsen. Semakin tinggi margin tataniaga maka bagian yang harga yang diterima oleh petani akan semakin kecil, karena farmer share memiliki hubungan negatif dengan margin tataniaga (Amalia, 2012). Secara rinci farmer share pada saluran tataniaga tomat di Kecamatan Sumberejo dapat dilihat pada Tabel 3 .

Tabel 3. Farmer share pada saluran tataniaga tomat di Kecamatan Sumberejo

\begin{tabular}{lccc}
\hline Saluran Tataniaga & $\begin{array}{c}\text { Harga di Tingkat Petani } \\
(\mathrm{Rp} / \mathrm{kg})\end{array}$ & $\begin{array}{c}\text { Harga di Tingkat Konsumen } \\
\text { Akhir }(\mathrm{Rp} / \mathrm{kg})\end{array}$ & $\begin{array}{c}\text { Farmer Share } \\
(\%)\end{array}$ \\
\hline Saluran tataniaga pola I & 6.000 & 9.000 & 66,67 \\
Saluran tataniaga pola II & 6.000 & 9.000 & 66,67 \\
Saluran tataniaga pola III & 5.000 & 9.000 & 55,56 \\
\hline
\end{tabular}

Sumber: Data diolah, 2020

Nilai farmer share pada saluran tataniaga pola I $(66,67 \%)$, saluran tataniaga pola II $(66,67 \%)$, dan saluran tataniaga pola III $(55,56 \%)$, nilai farmer share pada saluran tataniaga I dan II cukup menguntungkan dibandingkan dengan saluran tataniaga III. Nilai farmer share yang tinggi yang diperoleh produsen/petani pada suatu saluran tataniaga, maka dapat dikatakan saluran tataniaga tersebut dinilai lebih efisien (Fikri, 2013). 


\section{Ratio profit margin}

Ratio profit margin atau rasio keuntungan dan biaya menunjukkan nilai dari keuntungan yang diterima dibandingkan dengan biaya tataniaga yang dikeluarkan oleh setiap lembaga tataniaga. Semakin menyebar rasio keuntungan dan biaya, maka dari segi operasional sistem tataniaga dapat dikatakan efisien (Noer et al, 2018). Secara rinci rasio keuntungan dan biaya pada setiap lembaga tataniaga di Kecamatan Sumberejo dapat dilihat pada Tabel 4.

Tabel 4. Rasio keuntungan dan biaya pada setiap lembaga tataniaga

\begin{tabular}{cccc}
\hline \multirow{2}{*}{ Lembaga Tataniga } & Saluran Tataniaga & & \\
\cline { 2 - 4 } & I & II & III \\
\hline Pedagang Pengumpul & $1.042,76$ & & 596,63 \\
$\mathrm{Li}$ & 457,24 & 403,37 \\
$\mathrm{Ci}$ & 2,28 & & 1,48 \\
$\mathrm{Rasio} \mathrm{Li} / \mathrm{Ci}$ & & & $1.328,11$ \\
\hline Pedagang Besar & & 835,96 & 171,89 \\
$\mathrm{Li}$ & & 164,04 & 7,73 \\
$\mathrm{Ci}$ & & 5,10 & $1.060,41$ \\
$\mathrm{Rasio} \mathrm{Li} / \mathrm{Ci}$ & & $1.675,71$ & 439,59 \\
\hline Pedagang Pengecer & 520,07 & 324,29 & 2,41 \\
$\mathrm{Li}$ & 979,93 & 5,17 &
\end{tabular}

Sumber : Data Primer diolah, 2020

Keterangan :

Li : Keuntungan $\quad \mathrm{Ci}$ : Biaya Tataniaga

Perhitungan nilai rasio keuntungan dan biaya pada setiap saluran tataniaga yaitu saluran tataniaga I, II, dan III menunjukkan adanya persebaran keuntungan yang merata, karena nilai rasio keuntungan yang diperoleh di setiap saluran tataniaga lebih besar dari 0 (Justiceawan et al, 2020). Berdasarkan penjelasan diatas maka dapat disimpulkan bahwa rasio keuntungan dan biaya yang terbesar yaitu terdapat pada saluran tataniaga III dengan nilai sebesar 11,62. Hal ini berarti bahwa setiap biaya sebesar Rp 1/kg yang dikeluarkan akan menghasilkan keuntungan sebesar Rp 11,62.

\section{Efisiensi saluran tataniaga}

Analisis efisiensi saluran tataniaga yang digunakan pada penelitian ini adalah analisis operasional (teknis), dan cara untuk mengetahui efisiensi tataniaga ini yaitu dengan menggunakan 3 indikator sebagai perbandingan menentukan saluran tataniaga yang efisien di Kecamatan Sumberejo. Indikator yang digunakan yaitu diantaranya marjin tataniaga, farmer share, dan rasio keuntungan terhadap biaya. Berikut ini indikator efisiensi tataniaga tomat pada masing-masing saluran tataniaga di Kecamatan Sumberejo dapat dilihat pada Tabel 5.

Tabel 5. Nilai efisiensi tataniaga pada masing-masing saluran tataniaga tomat di Kecamatan Sumberejo

\begin{tabular}{ccccccc}
\hline Saluran tataniaga & $\begin{array}{c}\text { Keuntungan } \\
(\mathrm{Rp} / \mathrm{Kg})\end{array}$ & $\begin{array}{c}\text { Total biaya } \\
(\mathrm{Rp} / \mathrm{Kg})\end{array}$ & $\begin{array}{c}\text { Margin } \\
(\mathrm{Rp})\end{array}$ & $\begin{array}{c}\text { Farmer } \\
\text { Share }(\%)\end{array}$ & $\begin{array}{c}\text { Ratio profit } \\
\text { margin }\end{array}$ & EP (\%) \\
\hline I & $1.562,83$ & $1.437,17$ & $3.000,00$ & 66,67 & 2,81 & 15,97 \\
II & $2.511,67$ & 488,33 & $3.000,00$ & 66,67 & 10,26 & 5,43 \\
III & $2.985,16$ & $1.014,84$ & $4.000,00$ & 55,56 & 11,62 & 11,28 \\
\hline
\end{tabular}

Sumber: Data diolah, 2020

Efisiensi pemasaran juga dapat dihitung dengan perbandingan antara biaya pemasaran dengan nilai dari produk tomat sehingga diperoleh nilai efisiensi pemasaran pada masing-masing saluran tataniaga I, II, 
dan III di Kecamatan Sumberejo masing-masing sebesar 15,97\%, 5,43\%, dan 11,28\%. Menurut penelitian Rosmawati (2011) menyebutkan bahwa kaidah keputusan pemasaran dikatakan efisien apabila nilai EP = 033\%. Hasil penelitian ini menunjukkan bahwa perhitungan efisiensi pemasaran dari setiap saluran tataniaga dapat dikatakan efisien, karena EP yang diperoleh memenuhi kaidah keputusan pemasaran yang efisien, yaitu masing-masing sebesar $15,97 \%, 5,43 \%$, dan $11,28 \%$. Namun dari ketiga saluran tataniaga tersebut akan dipilih saluran yang lebih efisien berdasarkan persentase efisiensi pemasaran.

Berdasarkan perhitungan efisiensi pemasaran saluran tataniaga pola II memiliki nilai efisiensi pemasaran dengan persentase yang paling kecil yaitu 5,43\%. Sehingga dapat disimpulkan bahwa saluran tataniaga pola II lebih efisien dibandingkan dengan saluran tataniaga pola I dan III. Hal ini mengacu pada penelitian terdahulu yang telah dilakukan yaitu penelitian Sudianyana (2015) yang menyatakan bahwa saluran tataniaga yang efisien yaitu saluran yang nilai persentasenya paling sedikit. Saluran tataniaga tomat yang telah terbentuk di Kecamatan Sumberejo memiliki tiga pola saluran tataniaga, saluran tataniaga yang paling efisien dari ketiga saluran tersebut berdasarkan indikator nilai margin tataniaga, nilai farmer share, rasio keuntungan dan biaya, serta perhitungan menggunakan rumus efisiensi pemasaran maka saluran tataniaga pola II dapat dikatakan saluran yang lebih efisien dibandingkan dengan saluran tataniaga pola I dan saluran tataniaga pola II.

\section{Elastisitas Transmisi Harga}

Analisis elastisitas transmisi harga dapat diperoleh dengan melakukan analisis regresi sederhana menggunakan software SPSS. Secara rinci hasil analisis regresi harga pada tingkat petani dan tingkat konsumen untuk mengetahui nilai elastisitas transmisi harga dapat dilihat pada Tabel 5. Rata- rata harga tomat pada tingkat petani dan pedagang pengecer masing-masing adalah sebesar Rp 4.153/kg dan Rp $7.117 / \mathrm{kg}$.

Tabel 6. Hasil analisis regresi elastisitas transmisi harga

\begin{tabular}{ll}
\hline Uraian & Koefisien \\
\hline Konstanta & 892.572 \\
Koefisien $(\beta)$ & 0,458 \\
$\mathrm{R}^{2}$ & 0,299 \\
\hline
\end{tabular}

Sumber: Data diolah, 2020

Koefisien regresi $(\beta)$ yang dihasilkan dari hasil analisis regresi menggunakan SPSS diperoleh sebesar 0,458 , sehingga dapat dihitung nilai elastisitas transmisi harga (ET) dengan rumus sebagai berikut:

$$
\begin{aligned}
& \mathrm{Et}=\beta \frac{\mathrm{Pr}}{\mathrm{Pt}} \\
& \mathrm{Et}=0,458 \times \frac{7.117}{4.153} \\
& \mathrm{Et}=0,785
\end{aligned}
$$

Nilai elastisitas transmisi harga yang diperoleh berdasarkan rumus persamaan diatas yaitu sebesar 0,785. Nilai elastisitas transmisi harga ini menunjukkan harga yang bersifat inelastis, karena diperoleh nilai elastisitas transmisi harga lebih kecil dari satu $(E t<1)$. Keadaan ini menunjukkan bahwa laju perubahan harga di tingkat konsumen (pengecer) lebih kecil dibandingkan laju perubahan harga di tingkat produsen (petani). Hal ini menggambarkan pelaku pemasaran merupakan pemasaran bersaing tidak sempurna (Prayitno et al, 2013). Dengan kata lain, sistem pemasaran yang berlangsung tidak efisien. Nilai Et $<1$ memilki arti bahwa perubahan harga sebesar $1 \%$ di tingkat pedagang pengecer akan mengakibatkan perubahan harga lebih kecil dari $0,785 \%$ di tingkat petani. Nilai elastisitas transmisi harga yang diperoleh menunjukkan adanya kepekaan perubahan harga pada tingkat petani lebih kecil daripada perubahan harga di 
tingkat pedagang pengecer. Nilai elastisitas transmisi harga juga dapat menyatakan tingkat kompetisi suatu pasar atau struktur pasar yang terbentuk.

Nilai Et sebesar 0,785 (lebih kecil dari satu) hasil penelitian ini sesuai dengan penelitian yang sudah dilakukan Paramita et al (2019), mengenai elastisitas transmisi harga tomat di Kabupaten Lampung Barat, hasil analisis transmisi harga $0,44(\mathrm{Et}<1)$ yang berarti perubahan harga sebesar 1\% di tingkat pengecer atau konsumen akhir, akan mengakibatkan perubahan harga kurang dari $1 \%$ di tingkat petani/produsen. Nilai elastisitas transmisi harga yang kurang dri angka $1 \%$ maka dapat diartikan bahwa perubahan harga yang terjadi di tingkat pedagang tidak di transmisikan dengan baik ke tingkat harga petani (Kusumah, 2018).

\section{Struktur Pasar}

Identifikasi struktur pasar di Kecamatan Sumberejo dapat diketahui dengan melihat banyaknya jumlah penjual dan pembeli, mengetahui sifat dari produk tomat yang dilihat dari sudut pandang pembeli, mengetahui informasi tentang harga tomat di pasar, dan hambatan dalam keluar dan masuk pasar. Pada tingkat petani dan pedagang pengecer struktur pasar yang terbentuk yaitu struktur pasar oligopsoni murni. Pada tingkat pedagang besar struktur pasar yang terbentuk yaitu struktur pasar oligopoly, dan pada tingkat pada pengecer cenderung menghadapi pasar oligopsoni.

Berdasarkan penjelasan mengenai struktur pasar yang telah diidentifikasikan dari masing-masing lembaga tataniaga yang terlibat dalam pemasaran tomat, maka dapat disimpulkan bahwa struktur pasar pada tataniaga komoditas tomat yaitu memiliki struktur pasar yang mengarah pada pasar persaingan tidak sempurna yaitu pasar oligopsoni. Pasar persaingan tidak sempurna (imperfect market) salah satunya pasar oligopsoni dapat menyebabkan bargaining position atau posisi tawar yang lemah karena hanya bertindak sebagai penerima harga (price taker). Solusi atau cara untuk meningkatkan posisi tawar atau daya saing petani yang lemah yaitu dengan adanya pembentukan pasar bersama atau lembaga ekonomi yang dikelola oleh kelompok tani, dan disertai peningkatan kemampuan kelompok tani tersebut agar mampu menembus pasar yang ada (Hasanuddin et al, 2009).

\section{Indeks monopoli (MPI)}

Indeks monopoli atau monopoly indeks dapat menunjukkan suatu struktur pasar, indeks monopoli juga dapat digunakan untuk mengukur efisiensi pemasaran berdasarkan kinerja dari masing-masing lembaga pemasaran (Ulfa \& Masyhuri, 2018). Nilai indeks monopoli ini merupakan nilai kuantitatif yang digunakan untuk menunjukkan tingkat monopoli dalam suatu struktur pasar. Seberapa besar tingkat dominasi dari lembaga pemasaran dalam suatu saluran pemasaran dapat ditunjukkan dengan adanya indeks monopoli. Nilai indeks monopoli yang semakin besar dapat mengindikasikan bahwa semakin dominan pengaruh dari lembaga pemasaran pada suatu saluran pemasaran (Kuntadi \& Jamhari, 2012). Indeks monopoli ini dapat diukur dengan menggunakan rumus sebagai berikut:

$$
\text { MPI }=\frac{m}{c}
$$

Rumus MPI menunjukkan nilai perbandingan antara $\mathrm{m}=$ margin tataniaga, dan $\mathrm{Cv}=$ biaya variabel. Hasil perhitungan indeks monopoli akan disajikan dengan cara menghitung MPI pada masing-masing lembaga tataniaga di setiap saluran tataniaga yang terbentuk.

Tabel 7. Rata-rata nilai indeks monopoli dari setiap saluran tataniaga

\begin{tabular}{llll}
\hline Lembaga tataniaga & Margin $(\mathrm{Rp})$ & Biaya variabel $(\mathrm{Rp})$ & MPI \\
\hline Pedagang pengumpul & $1.250,00$ & 363,16 & 3,44 \\
Pedagang besar & $1.000,00$ & 167,96 & 5,95 \\
Pedagang pengecer & $1.666,67$ & 581,27 & 2,86 \\
\hline
\end{tabular}

Sumber: Data diolah, 2020 
Tabel 7 menunjukkan rata-rata nilai indeks monopoli pada setiap lembaga tataniaga, tujuan perhitungan indeks monopoli ini yaitu bertujuan untuk menunjukkan keterlibatan lembaga tataniaga pada suatu saluran atau dominasi lembaga tersebut dalam penentuan harga (Setyaningsih et al, 2015). Nilai MPI diperoleh bahwa pedagang besar memiliki nilai indeks monopoli yang paling besar yaitu sebesar 5,95. Nilai indeks monopoli tersebut menunjukkan bahwa keterlibatan pedagang besar pada suatu kegiatan tataniaga paling mendominasi dalam hal penentuan harga. Nilai MPI yang lebih tinggi pada pedagang besar dapat menunjukkan tingkat monopoli atau dominasi dari lembaga pemasaran dalam suatu rantai pemasaran. Artinya dalam hal ini pedagang besar memiliki dominasi atau kekuatan dalam pengambilan keputusan harga jual pada kegiatan tataniaga tomat. Nilai indeks monopoli yang diperoleh oleh pedagang pengumpul yaitu sebesar 3,44 sedangkan nilai indeks monopoli yang diperoleh oleh pedagang besar dan pedagang pengecer masing-masing yaitu sebesar 5,95 dan 2,87. Nilai indeks monopoli tersebut menggambarkan bahwa MPI diatas 1 menunjukkan bahwa agen pemasaran telah menerapkan fungsi pemasaran secara efisien.

Berdasarkan nilai indeks monopoli yang telah diperoleh dapat disimpulkan bahwa masih terdapat kekuatan monopoli di tingkat lembaga tataniaga yaitu pedagang besar dalam kegiatan tataniaga tomat. Nilai indeks monopoli ini juga menunjukkan kekhawatiran petani selama ini mengenai lembaga tataniaga yang memiliki monopoli yang kuat dalam mendominasi pasar atau penentuan harga jual. Keadaan ini menunjukkan bahwa posisi petani sebagai produsen dalam kegiatan tataniaga tomat cenderung lemah. Monopoli yang kuat pada tingkat pedagang maka harus dicegah atau diminimalisir, sedangkan posisi tawar petani yang lemah dalam hal ini maka harus ditingkatkan dengan beberapa upaya untuk meningkatkan posisi tawar petani tersebut. Upaya yang dapat dilakukan untuk meningkatkan posisi tawar petani yaitu dengan adanya koperasi unit desa (KUD), jika terdapat koperasi maka dapat menjadi penghubung kerjasama anatara petani tomat dan para pedagang, serta perlu adanya lembaga pengolahan hasil pertanian saat harga tomat turun atau adanya kelompok-kelompok industri untuk pengolahan hasil panen tomat itu sendiri (Novita, Yonariza, \& Wahyuni, 2019).

\section{KESIMPULAN}

Lembaga tataniaga menjalankan aktivitas penjualan tomat, pembelian tomat, pengangkutan, penimbangan, penanggungan risiko, pembiayaan, dan informasi pasar. Saluran tataniaga yang terbentuk di Kecamatan Sumberejo terdapat 3 saluran. Pada saluran tataniaga I, saluran tataniaga II, dan saluran tataniaga III masing-masing diperoleh margin sebesar Rp 3.000, Rp 3.000 dan Rp 4.000. Saluran tataniaga yang paling efisien yaitu saluran tataniaga yang pendek terdapat pada saluran tataniaga II. Berdasarkan beberapa indikator dan nilai efisiensi pemasaran maka saluran tataniaga II merupakan saluran yang efisien dibandingkan saluran I dan III. Nilai elastisitas transmisi harga yang diperoleh pada harga tomat di tingkat petani dan pedagang pengecer yaitu sebesar $0,785(\mathrm{Et}<1)$ yang berarti terjadi elastisitas harga yang bersifat inelastis. Secara umum struktur pasar tomat mengarah pada pasar persaingan tidak sempurna yaitu pasar oligopsoni.

Kelembagaan kelompok tani sebaiknya dapat membangun koperasi simpan pinjam untuk membantu permodalan petani dan mengurangi keterikatan hutang atau pinjam modal dari pedagang.

\section{DAFTAR PUSTAKA}

Amalia, A. N. 2012. Analisis Tataniaga Wortel (Daucus Carota L ) di Kecamatan Pacet Kabupaten Cianjur, (Skripsi). Bogor. Fakultas Ekonomi dan Manajemen Institut Pertanian Bogor.

Andhika, R., Hasnudi dan Ginting, N. 2014. Pemasaran Daging Sapi Di Kabupaten Karo ( The Influence of Chain Efficiency Marketing Beef Cattle in The Karo Regency ), Jurnal peternakan integratif , 3(2), pp. 224-234. 
Anindita, R. 2017. Pemasaran Produk Pertanian. Yogyakarta. CV Andi.

Arikunto, S. 2008. Prosedur Penelitian Suatu Pendekatan Praktik. Jakarta. PT Rineka Cipta.

Badan Pusat Statistik dan Direktorat Jendral Hortikultura. 2018. Indonesia.

BPS Provinsi Lampung. 2016. Lampung Dalam Angka. Bandar Lampung.

BPS Kabupaten Tanggamus .2018. Kabupaten Tanggamus Dalam Angka (Tanggamus Regency in Figures), Lampung.

Data Harga Rata- Rata Tomat di Tingkat Produsen dan Eceran. 2018-2020, Dinas Pertanian dan Pangan Kabupaten Tanggamus.

Elisa, Hadayani dan Effendy. 2016. Analisis Pemasaran Usahatani Tomat Kelurahan Boyaoge Kecamatan Tatanga Kota Palu, J.Agroland, 23(1), pp. 77-85.

Fikri, M. 2013 Sistem Tataniaga Tomat (Kasus di Desa Tugumukti, Kecamatan Cisarua, Kabupaten Bandung Barat), (Skripsi). Bogor. Fakultas Ekonomi dan Manajemen Institut Pertanian Bogor.

Fitriani, Ismono, H.dan Rosanti, N. 2011. Produksi Dan Tataniaga Beras Di Propinsi Lampung, 5(1), pp. 111.

Hasanuddin, T., Trully, D. dan Endaryanto, T. 2009. Akar Penyebab Kemiskinan Petani Hortikultura di Kabupaten Tanggamus, Propinsi Lampung, Jurnal Agrikultura, 20(3), pp. 164-170.

Justiceawan, M. W., Apriyani, M. dan Saty, F. M. 2020. Analisis Efesiensi Tataniaga Kopi di Desa Ngarip Kecamatan Ulubelu Kabupaten Tanggamus, Journal of food system agribusiness, 4(1), pp. 17-24.

Kuntadi, E. B. dan Jamhari. 2012. Efisiensi Pemasaran Cabai Merah Melalui Pasar Lelang Spot di Kabupaten Kulonprogo, Yogyakarta, Jurnal Sosial Ekonomi 1(1), pp. 95-101.

Kusumah, T. A. 2018. Elastisitas Transmisi Harga Komoditas Cabai Merah di Jawa Tengah, Economics Development Analysis Journal, 7(3), pp. 294-304.

Noer, I., Zaini, M. dan Fatih, C. 2018. Tataniaga Pertanian. Bandar Lampung . UP Politeknik Negeri Lampung.

Novita, N., Yonariza dan Wahyuni, S. 2019. Penguatan Kelembagaan Petani Terhadap Peningkatan Posisi Tawar Petani Gambir di Nagari Koto Lamo Kecamatan Kapur Ix Kabupaten 50 Kota, Journal of Socio Economic on Tropical Agriculture, 1(3), pp. 57-66.

Paramita, Y. S., Hasyim, A. I. dan Affandi, M. I. 2019. Analisis Rantai Pasok Tomat Di Kecamatan Sukau Kabupaten Lampung Barat, 7(4), pp. 499-506.

Prayitno, A. B., Hasyim, A. I. dan Situmorang, S. 2013. Efisiensi pemasaran cabai merah di kecamatan adiluwih kabupaten pringsewu provinsi lampung', J. Jiia, (1), pp. 53-59.

Rahayu, S. 2018. Analisis Pemasaran Komoditas Nanas (Ananas comosus (L) Merr.) Berbasis Structure Conduct Performance (SCP) di Kecamatan Ngancar Kabupaten Kediri, (Skripsi). JawaTimur. Fakultas Pertanian Universitas Jember.

Rosmawati, H. 2011. Analisis Efisiensi Pemasaran Pisang Produksi Petani di Kecamatan Lengkiti Kabupaten Ogan Komering Ulu, Jurnal Agribisnis, 3(5), pp. 1-9. 
Setyaningsih, N. N., Hardyastuti, S. dan Suryantini, A. 2015. Analisis Rantai Nilai Agroindustri Mocaf (Modified Cassava Flour) Di Kabupaten WonogirI, 1(1), pp. 63-74.

Sinaga, S. C. dan Dewi, N. 2016. Pemasaran Buah Nenas (Kajian Struktur, Perilaku, Dan Penampilan Pasar) Di Desa Kualu Nenas Kecamatan Tambang Kabupaten Kampar, 13(1), pp. 38-50.

Soekartawi. 2002. Prinsip Dasar Ekonomi Pertanian. Jakarta. PT RajaGrafindo Persada.

Sudianyana, I. K. H. 2015. Analisis Efisiensi Saluran Pemasaran Komoditas Anggur Di Desa Banyupoh Kecamatan Gerokgak Tahun 2014, 5(1).

Sutarni, Saty, F. M. dan Unteawati, B. 2018 Distribution Analysis of the Supply Chain of Catfish (Pangasius) Agribusiness in Kota Gajah District, Central Lampung, Indonesia, in, pp. 1-15. doi: 10.1088/1755-1315/209/1/012023.

Ulfa, A. N.dan Masyhuri . 2018. Rice Marketing Efficiency In Sragen Regency Efisiensi Pemasaran Beras Di Kabupaten Sragen, J. Agro Ekonomi, 29(2), pp. 287-298. 